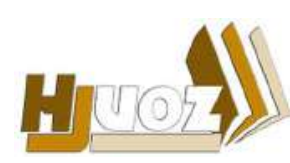

hjuoz.uoz.edu.krd p-ISSN: 2410-7557 e-ISSN: 25185128
كُوْفارا زانستيّن مروّايهتى يا زانكوّيا زاخوّ

مجلة العلوم الانسانية لجامعة زاخو

Humanities Journal of University of Zakho (HJUOZ)

Vol. 6, No. 1, Part 2, pp. 210-224, Mar.-2018

\title{
أثر برنامج ارثادي انتقائي في تخفيف السلوك العدواني لدى طلبة المرحلة الاساسية
}

\author{
جيهان سعيد عادل * و نهاد عبيد حسين \\ جامعة دهوك، كلية التربية الاساسية، قسم علم النفس، اقليم كردستان - العراق.
}

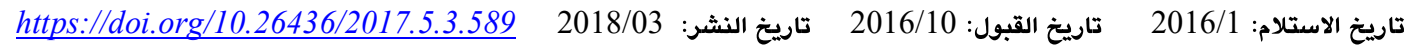

الملخص:

السلوك العدواني وهو ظاهرة واسعة الانتشار، وتكاد تميزها العصر نتيجة لتلك الصراعات والتوترات التي تعصف بمنطقنا، والتي حتما

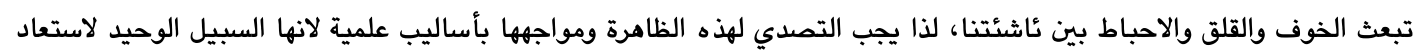

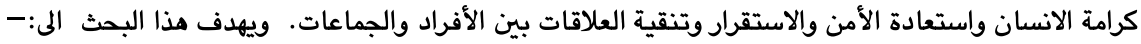

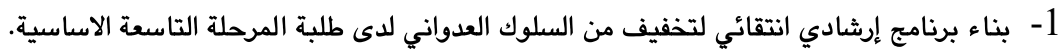

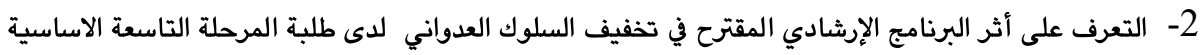
ويتطلب ذلك التحقق من الفرضية الصفرية الآتية : - لا توجد فروق ذات دلالة إحصائية بين درجات المجموعة التجريبية ويين درجات المجموعة الضابطة على مقياس سلوك عدواني بعد تطبيق البرنامج الإشادي.

لغرض اختبار فرضية البحث استخدم الباحثان التصميم التجريبي ( تصميم المجموعة التجريبية والمجموعة الضابطة مع اختبار قبلي - بعدي )، وتكونت عينة البحث من (20 ) طالب وذع بطريقة عشوائية على مجموعتين تجريبية وضابطة. وقد قام الباحثان ببناء

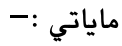
1- اداة لقياس سلوك العدواني اذ بلغ عدد فقرات اداة (42) فقرة، وقد ثم التحقق من صدق الأداة عن طريق الصدق الظاهري وأما الثبات فقد أوجد بطريقة التجزئة النصفية اذ بلغت قيمته (0,87) للأداة.

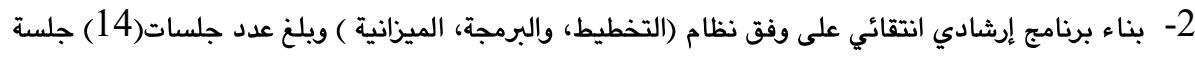

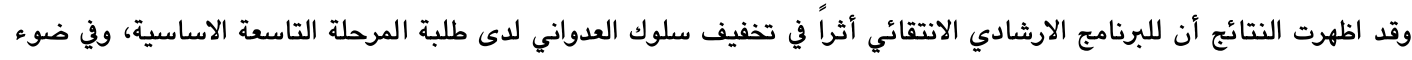

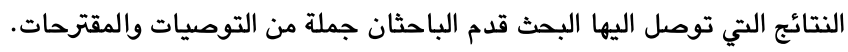

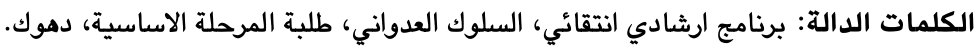

والعدوان ظاهرة انسانية معقدة كانت موجودة منذ القدم إلا انها أصبحت سمة العصر، حيث تعددت أشكالها وأختلفت مجالاتها، مما يتطلب الاهتمام من الباحثين ودراسة هذه الظاهر لتقديم التفسيرات العلمية

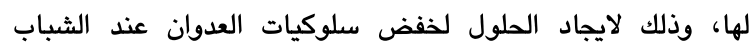

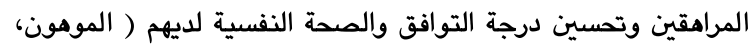

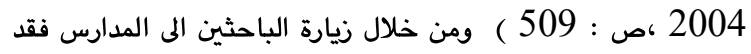

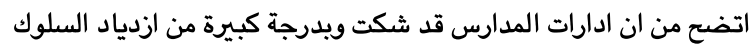

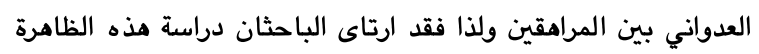

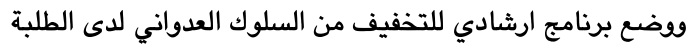

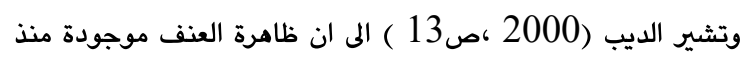

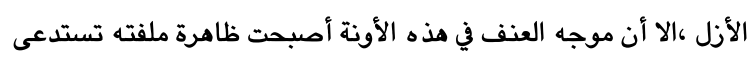

\section{1.مشكلة البحث}

السلوك العدواني وهو ظاهرة واسعة الانتشار، وتكاد تميزها العصر

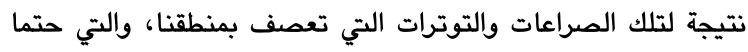
تبعث الخوف والقلق والاحباط بين المراهقين مما يجعل الأجواء مهيأة لمزيد من العدوان على اختلاف أشكالها.

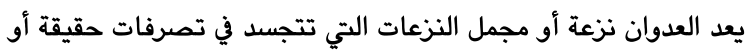

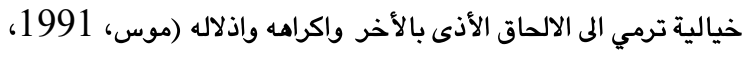
ص : 29 ). وأصبح العدوان مظهر من مظاهر الحياة العصرية ومؤشراً

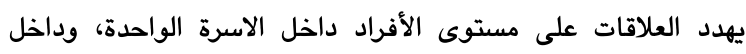

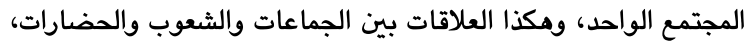


مع هذه المرحلة بطريقة سليمة، إذ يتطلب منا تأهيل المراهق للمستقبل وإرشاده على بعض المهارات الحياتية المهمة والعمل على تخفيف من

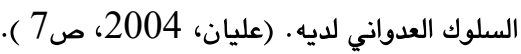
ظاهرة العدوان أصبحت مشكلة كبرى للإنسانية عموما وقضية العالم الأولى لأنها تهددت أمنة النفسي والاجتماعية لذا يجب التصدي لهذه الظاهرة ومواجهها بأساليب علمية لانها سبيل الوحيد لاستعاد كرامة الانسانية واستعادة الأمن والاستقرار وتنقية العلاقات بين الأفراد

والجماعات

ويلخص الباحثان أهمية هذه البحث في ماياتي :1- أهمية وخطورة الموضوع الذي نتصدى له، أي أهمية التصدى لظاهرة السلوك العدواني التي اجتاحت إنسانية الإنسان وعطلت عقله ومددت أمنة النفسي والاجتماعي. 2- أهمية المرحلة التي يستخدمها مذه الدراسة والمتمثلة في المرحلة المرامقة تلك المرحلة التي لها من الاممية النفسية والتربوية والاجتماعية ما يجعلها جديرة باهتمام الباحثين نظر لكون مذه الشريحة تمثل رحح الامة وأملها وأساس تقدمها ورقيها ،كما انها تمثل من جانب اخر أكثر فئات المجتمع عرضه للتطرف نحو العدوان.

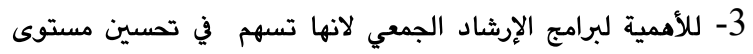
الصحة الانفعالية والتكيف مع الحياة وتعد وسيلة فعالة في مساعدة الجماعة الإرثادية على التخلص مما يواجهها من أزمات ومشاكل في جميع جوانب الحياة. 4- أهمية الإرثاد الانتقائي كأحد الاتجامات والتيارات الحديثة والفاعلة في التصدي للمشكلات وإعداد برنامج مع إرثادي انتقائي وتطبيقه لأول مرة في أقليم كوردستان للتقليل من مستوى سلوك عدواني لدى المراهقين حسب علم الباحثين.

\section{3. اهداف البحث}

$$
\text { يهدف البحث الحالي التعرف على مايأتي: }
$$

1.3. بناء برنامج إرثادي للتخفيف من السلوك العدواني لدى طلبة المرحلة التاسعة الاساسي. 2.3. التعرف على أثر البرنامج الإرشادي المقترح في تخفيف السلوك العدواني لدى طلبة المرحلة التاسعة الاساسية. ويتطلب ذلك التحقق من الفرضية الصفرية الآتية : 3.3. لاتوجد فروق ذات دلالة إحصائية بين درجات المجموعة التجريبية وبين درجات المجموعة الضابطة على مقياس السلوك لورك العدواني بعد تطبيق البرنامج الإرثادي.

\section{4. تحديد المصطلحات}

1.4. البرنامج يعرفه الباحثان اجرائيا انه مجموعة من الخبرات التعليمية التي يمارسها الأفراد بغرض خفض سلوكهم العدواني ،وهذه
الامتمام بها من جانب الباحثين لدراستها ومحاولة تقديم التفسيرات

المتعددة حتى نتمكن من ايجاد حلول مناسب للصد أو التقليل منها. وتشير غنيمة(2004، ص 1113 ) الى أن ظامرة العنف تتفش في حياتنا الاجتماعية والسياسية بشكل ملحوظه فالعنف لايقتصر على الجماعات الرافضة بل أصبح سمة مميزة لنمط التفاعل في الحياة العادية للأفراد. والسلوك العدواني هو سلوك متعلم ومكتسب أي انه استجابة متعلمة ولقد اكدت دراسة (هانري )1972 حيث أثبتت أن الأفراد الذين تعرضوا اللاحباط أظهروا عدوانا أكثر من الأخرون الذين لم يتعرضوا اللاحباط (الشريف ، 1990 ) ولكن سلوك العدواني سلوك متعلم يمكن تعديله ،أو تعليم الناشئة سلوكا" اكثر اتزانا"، ويحقق للمراهقين طموحاتهم وحاجاتهم دون الاصطدام مع الاخرين، ولكن الأمر يحتاج الى التوجية والارشاد، وخصوصاً الإرشاد الجماعي لما له من عظيم الأثر في نفوس المراهقين الذين مم في حاجة الى مساندة نفسية ومازرة

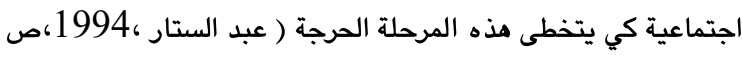
. 267

ومن هنا تبرز مشكلة البحث والمتمثل في الاجابة عن السؤال الاتية : - مل لبرنامج الارشادي دود في تخفيف سلوك العدواني لدى الطلبة

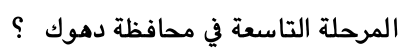

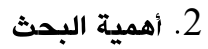

الارشاد النفسي فرع من فروع علم النفس التطبيقي ويهدف الى مساعدة الأفراد على التكيف النفسي والاجتماعي ومساعدة الاشخاص في مواجهة مايعترضهم من مشكلات ليتمكنوا من اعادة مسار حياتهم الى الحالة

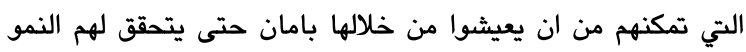

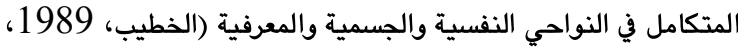
ص : 38 ). لهذا اصبحت الخدمات الإرشادية مؤشراً على تقدم المجتمع ورقية. والبرنامج الارشادي عنصر أساسي وجوهري في تنظيم العملية الارشادية، وتعد البرامج الإرشادية مهمة نتيجة للتطورات التي حصلت في مجال التربية وعلم النفس والتاكيد على تنمية شخصيات الأفراد في جميع النواحي الجسمية والنفسية والاجتماعية، وسواء كانت البرامج ارثادية انمائية أو وقائية أم علاجية ( عذاب، ورضا، 2011، ص:

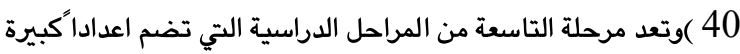
من المرامقات والمرامقين، لقد أكدت الديد من الابحاث تبرز أهمية هذه المرحلة في حياة الإنسان، لكونها تتميز بالنمو الواضح المستمر نحو النضج في كافة مظاهر وجوانب الشخصية، والتقدم نحو كل من النضج الجسمي والجنسي والعقلي والاستقلال الانفعالي والتطبيع الاجتماعي واكتساب المعايير السلوكية الاجتماعية الجديدة والقيام باتخاذ القرارات مهمة في حياته ( ملحم ،2004، ص : 324 ) ). ولاثك في أن نظرة المرامق للحياة ماتزال طرية غير ناضجة وافكاره قد تكون سطحية ومامشية وريما شاذة تتركز في اغلب على القشور، لذلك يجب أن نتعامل 


\section{5.}

يتحدد البحث الحالي بطلبة المدارس الاساسية ذات الدوام الصباحي ويقتصر على طلبة المرحلة التاسعة حصراً.

1.5 مفهوم العدوان:

تباينت تعريفات السلوك العدواني فلا يوجد تعريف واحد محدد للسلوك العدواني فكل باحث عرفه حسب خلفيته العلمية أو الثقافية. يرى فرويد (1959 )أن العدوانية هي من الغرائز الاساسية التي تتوجه الى

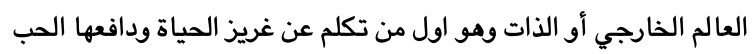

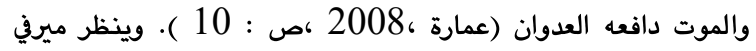
للعدوان على أنه استجابة فيها اصرار للتغلب على العقبات التي تقف في سبيل تحقيق رغبات الأفراد ومعنى ذلك أن الأفراد لايأتون

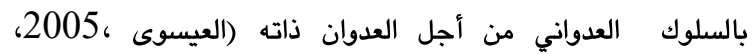
ص:35). يرى سكوت أن العدوان كأي استجابة أخرى سلوك متعلم أو مكتسب، فالفرد قد يتعلم الاستجابة للمواقف التي تجابهة بالعراك أوعدم العراك. يرى باوندا (1973 ) أن العدوان سلوك يهدف الى أحداث نتائج أو السيطرة من خلال القوة الجسدية أو اللفظية على الآخرين، وينتج عن أيذاء شخص أو تحطيم الممتلكات. (عبد المعطي ، 2001،ص: 441) كما ان هناك اجماع بين الباحثين أن العدوان

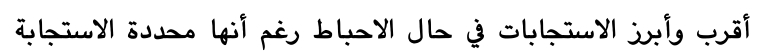
ومتعلمة وليست فطرية أوتلقائية ويتجة العدوان غالبا نحو مصدر الاحباط يهدف ازالة المصدر أو التغلب عليه ولكن المصدر قوياً لايستطيع الفرد أن يوجه اليه العدوان مباشرة (الخفاقي،

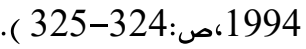

\section{5. مظاهر سلوك العدواني:}

مظاهر سلوك العدواني تتأثربعدة عوامل منها التنشئة الاجتماعية والجنس والعمر والمكانة الاجتماعية والاقتصادية، وأن العدوان في أي مظهر من مظاهره ريما يظهر نتيجة التشدد في وضع القيود والضوابط

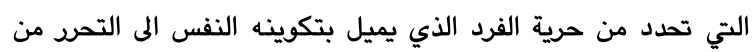
القيود ،وأن الذكور أكثر عدوانية في المظاهر العدوانية المختلفة بالمقارنة الى الاناث ،والعدوان الموجة نحو الذات لدى الاناث اكثر من الذكور،

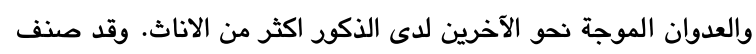
سابينفلد السلوك العدواني الى قسمين عدوان بدني وعدوان لفظي وصنف باندورا السلوك العدواني ثلاثة تصنيفات وهي عدوان بدني وعدوان لفظي وعدوان نحو الممتلكات. وصنف عبد الحميد السلوك العدواني الى عدوان بدني ،عدوان لفظي ،سلوك عدواني نحو الممتلكات

$$
\text { (عمارة ،2008 ،ص : 19 19-20 ). }
$$

يأخذ السلوك العدواني الأشكال التالية :
الخبرات معتمدة في مجملهاعلى مجموعة أنشطة متنوعة والتي تسعى

$$
\text { لتحقيق أهداف البحث. }
$$$$
\text { 2.4 البرنامج الارثادي عرفه: }
$$

1.2.4. عبد الخالق 2003 : مجموعة من الخطوات المنظمة والقائمة على أسس علمية ،تهدف الى تقديم الخدمات لمساعدة الأفراد أو الجماعات لفهم مشاكلهم والتوصل الى حلول بشانها ،وتنمية مهاراتهم وقدراتهم لتحقيق النمو السوي في شتى مجالات حياتهم ويتم في صورة جلسات منظمة في إطار من علاقة متبادلة متفهم بين المرشد والمسترشد

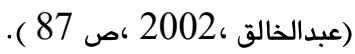
2.2.4 عارف 2003 هو نظام يعمل وفق نظريات الارشاد النفسي على مساعدة وتبصر الأفراد في فهم مشكلاتهم، والتي تؤدي الى سوء التوافق، ويعمل كذلك على تبصير الأفراد على حل هذه المشكلات ريما يحقق سعادة الفرد مع الآخرين، بحيث يصل الفرد الى أفضل مستوى هـى هده

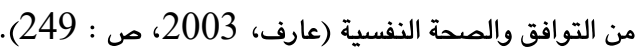
يعرف الباحثان البرنامج الإرشادي نظريا بأنه سلسلة من الخطوات

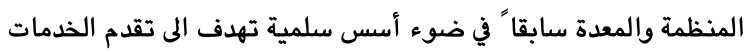
الأرشادية لعينة الدراسة من اجل تخفيف الى أقصى الدد ممكن من سلوك العدواني عن طريق استعمال أساليب وفنيات ارثادية انتقائية. 3.4. العدوان عرفه 1.3.4. الشريف 1999 :أي سلوك يصدره الفرد لفظيا" كان هذه السلوك أو بدنياً أو مادياً مباشراًأو غير مباشراً وحدده في المقام الأول

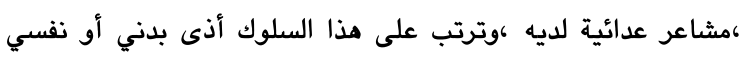

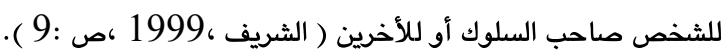
التعريف الاجرائي للسلوك العدواني يتبني الباحثان التعريف الاتي للعدوان : مو كل قول أو فعل أو تقرير لفعل أو إثارة يقصد به الحاق الأذى أو الدمار بالآخرين أو بذات الانسان نفسه، وهو يمثل الدرجة التي يحصل عليها الطالب من حيث المتغيرات المقاسة في مقياس السلوك

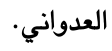
4.4 الإرشاد الانتقائي 1.4.4. عرفه أبو النور 2000 :هوشكل من أشكال الإرشاد النفسي قائم على نظرية العلاج النفسي الانتقائي الذي يعد نظاماً يقوم على النى تحديد المبادئ والاستراتيجيات الأساسية الفعالة للعلاجات النفسية الأخرى، وخاصة تلك الاسترتيجيات التي ثبت فعاليتها في علاج المشكلات وتلائم حاجات المسترثد (أبو النور ،2000 ،ص الصدئ، : 252). التعريف الاجرائي للارشاد الانتقائي مو بان الارشاد الانتقائي يمثل

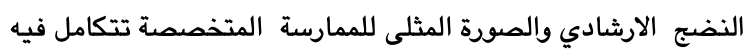
الفنيات الارشادية وتعمل على مواجهة الاختلافات والفرق والتغيرات في المواقف والحالات والمشكلات. 


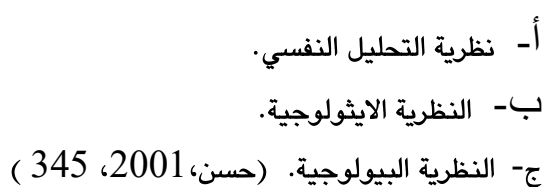

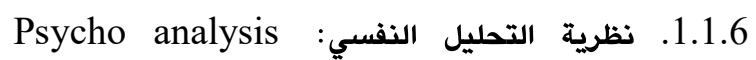
theory

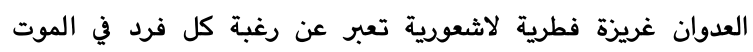

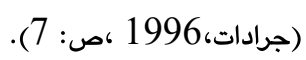

والعدوان كما يعتقد فرويد هوسلوك غريزي بهات يهدف إلى تفريغ الطاقة العدوانية الموجودة داخل جسد الإنسان، ويجب إشباعها تماما كما

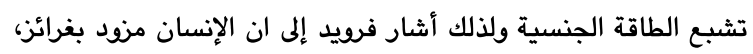

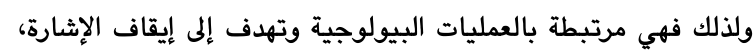

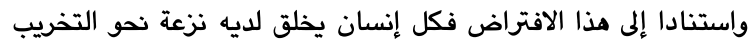

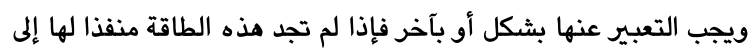
الخارج(البيئة) فهي توجه نحو الشخص نفسه (يعقوب، 263، 2002 أو 2002).

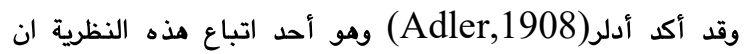

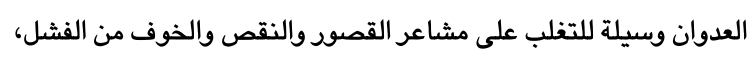
وإذا لم يتم التغلب على هذه المشاعر،عندئذ يصبح العدوان وسلوك

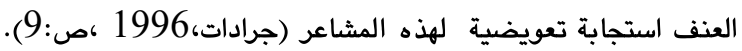

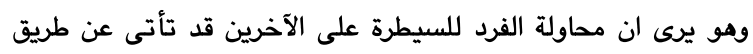

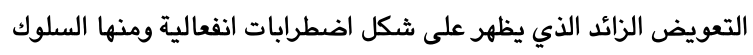

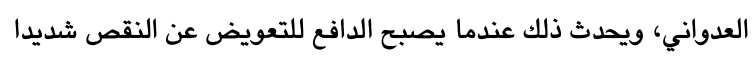

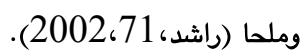

2.1.6. النظرية الايثولوجية:Ethnological theory (Ardary, 1966) وتمثل هذه النظرية منحنيين مثل ارداري:

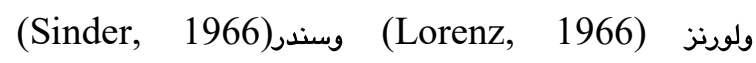
وستور (Storr, 1968) وتبركن (Tenbbergen, 1968) ومند (Hind, 1970) فطري غريزي، ويرى شأنه شأن فرويد، ضرودة إطلاق الطاقة العدوانية

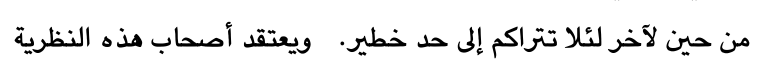

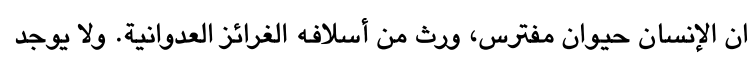

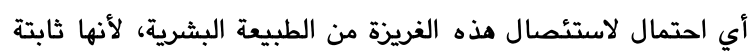

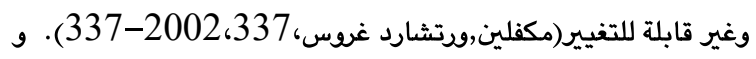

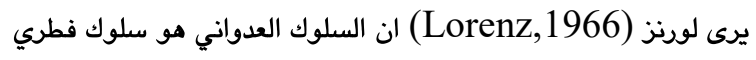
ناجم عن عمليات الانتقاء الطبيعي، وهذا معناه ان الطبيعة اختارت

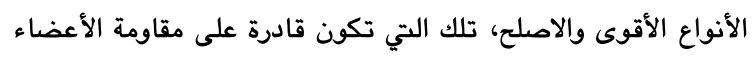

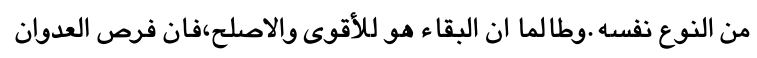

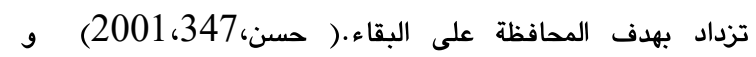

(Mummedey,1988,p.266)
1- العدوان الجسدي : ويقصد به السلوك الجسدي المؤذي الموجة

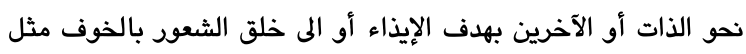

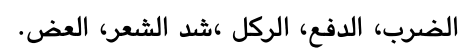
2- العدوان اللفظي : يقف عند حدود الكلام الذي يرافق الغضب الشب الفرب والشتم والسخرية والتهديد. 3- العدوان الرمزي : يشمل التعبير بطرق غير لفظية عن احتقار

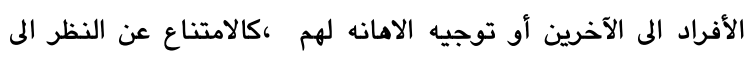

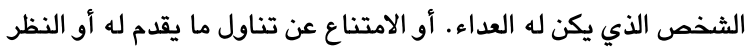
بطريقة ازدراء وتحقير. 4- العدوان مباشرة وغير مباشرة : وهناك اشكال اخرى من سلوك وكرئ العدواني ويكون على أساس الطريقة التي يعبر بها عن السلوك العدواني وأساس الشخص الذي يوجه له السلوك العدواني. 3.5 أسباب السلوك العدواني:

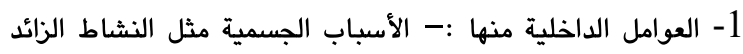

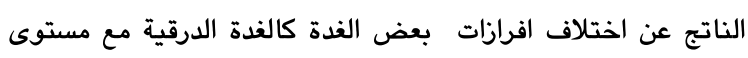
منخفض من الذكاء حيث لايمكن الفرد من تصريف نشاطه الزائد في

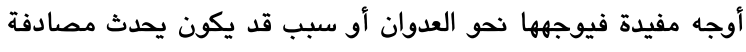

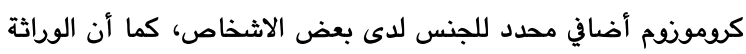

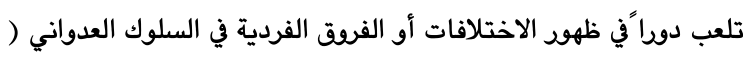

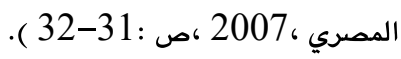
2- العوامل الخارجية تتعلق بالأسرة وطريقة التنشئة وقد يكون التسلط :

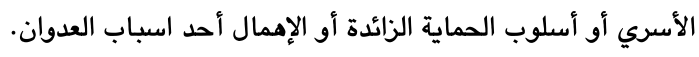

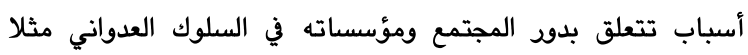

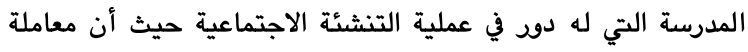
المعلمين للطلاب له أثر كبير في تشكيل السلوك العدوانية

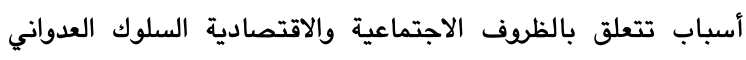
يختلف أيضا باختلاف المستوى الاقتصادي والاجتماعي.

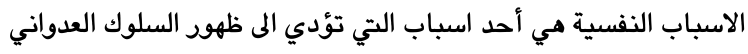

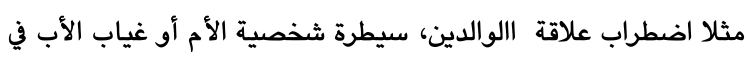
تربية الطفل، الرغبة في اثبات الذات والشعور بالذنب ،الفشل وعدم الفران

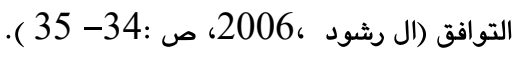

\section{6. النظريات التي فسرت السلوك العدواني}

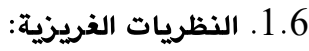

تصور الفيلسوف البريطاني توماس هويز Thomas) (ان الناس يميلون بالفطرة إلى التنافس والعدائية وانهم لا يهتمون إلا بما ينفعهم ويساعدهم على التفوق على الآخرين

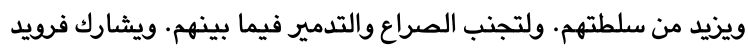
وكونراد لورنز آراء هويز التشاؤمية بشأن الطبيعة البشرية ومن أهم

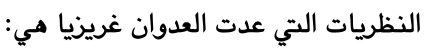


وان الفكرة الأساسية لهذه النظرية ترى إن العدوان سلوك متعلم مثله مثل أي سلوك اجتماعي آخر. إذ ان السلوك العدواني يكتسب من خلال مشاهدة النماذج وما تظهره من عدوان تجاه البيئة المحيطة بها.وان النمذجة لا تتطلب القابليات المعرفية الادراكية ويستطيع الفرد تقليد بعض أفعال الآخر بصورة آلية ،لكنه يعجز عن أخذ دود الآخر ما لم

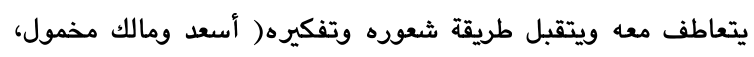

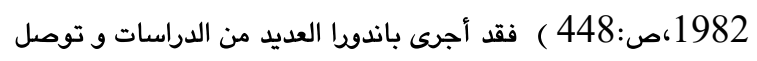
إلى ان الفرد ينمذج العدوان، ففي إحدى التجارب التي أجراما على أطفال الروضة التي قسمها إلى خمسة مجاميع ،شاهدت المجاميع الأريع نماذج إنج عدوانية أما الخامسة فقد تعرضت لمشاهد إنسانية يتصرف فيها بطريقة غير عدوانية. وتوصل باندورا الى ان المجاميع الأربع كانت اكثر عدوانية

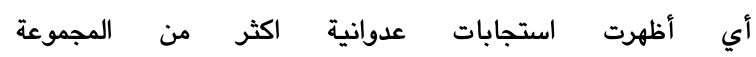
الضابطة(حسن، 2001 ،ص: 351 ). وقد افترض باندورا وروس(Bandura \&Ross,1963) ان الأطفال يتعلمون السلوك العدواني عن طريق ملاحظة نماذج العدوان عند ولدون الأبوين ومن ملاحظة أفلام التلفزيون والسينما وفي القصص التي يقرؤها والحكايات التي يسمعها.

\section{7. - الإرثاد الأنتقائي}

الإرشاد الانتقائي لم يعد نظرية إرثادية ربل إنها أصبح اتجاماًمن الاتجاهات الرئيسية للإرثاد النفسي يهتم به العديد من النظريات، والتي جاءت اعتماداً على فكرة انه لايوجد اتجاها إرشادياً أو نظرية إرشادية واحد قادرة بمفردما على التعامل بنفس الدرجة من الكفاءة والفعالية مع الجوانب المتعددة لمشكلات المسترشد وشخصياتهم. والإرشاد الانتقائي منظومة ذات طابع متسق من الفنيات الإرشادية والعلاجية تنتمي فيها كل فنية نظرية علاجية خاصة بها إلا أن أنتقاء هذه الفنيات تتم بشكل تكاملي بحيث تسهم كل منها في علاج جانب من جوانب اضطراب شخصية المسترشد (عزب، 2002، ص :5 :5 ). ويرى الباحثان ان الانتقائية هو اتجاه إرثادي الذي يعد اليوم من أهم

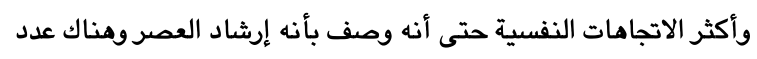
من العوامل التي ساهمت في هذا من أهمها تطور النظريات الكلاسيكية القديمة كالتحليلية على يد أنصارما الجدد والسلوكية على يد سكنر وياندوا وظهور الاتجاه الانساني واعتباره القوة الثالثة في علم النفس لئل وظهور النظريات المعرفية كنظرية أليس ونظرية ريمي، وانفصال عدد من أبرزعلماء الاتجاهات الرئيسية النفسية عن اتجاهاتهم وتبنيهم هذا الاتجاه، وتطور الدراسات النفسية والممارسات الإرشادية العملية التراكم البحثي الاسهامات الجادة التي قدمها أبرز علماء هذا الاتجاه كاسهامات ثون ولازاروس ومارت يمثل الارثاد الانتقائي الارشاد في ثويه الجديد المتكامل الناضج والتيار الارشادي المرن والمنقتح لكل اضافة ولكل إسهام جاد في الإرشاد النفسي ليكون النظام المتناسق الذي يوم بانتقاء
3.1.6. النظرية البيولوجية: Biological theory أصحاب وجهة النظر هذه ان منطقة الفص الجبهي والجهاز الطرفي المسؤول عن ظهور السلوك العدواني عند الإنسان، وعند استئصال بعض التوصيلات العصبية في هذه المنطقة عن المخ ،أدى إلى خفض الفض التوتر والغضب والعنف،وأدى إلى حالة من الهدوء والاسترخاء ويحدث عكس ذلك عندما تستثار بواسطة التيار الكهربائي(جرادات، 1996 ص:8). (1) ويرى سكنر أستاذ علم الهرمونات ان زيادة إفرازات الفص الأمامي للغدة النخامية يصاحبه توتر واندفاع إلى العدوان.(حجازي 1988، كص:55) وتذكر (دافيدوف)أن لأجهزة المخ دورا في العدوان في أداء وظيفتها،ويمكن ان تمنع الدوائر العصبية من أداء وظيفتها (دافيدوف، 1983 ،515) فعندما قام علماء النفس هإثارة الجزء الأمامي من الهيبوثلاموس لقطة، قامت بمهاجمة الفأر. (الزغبي،

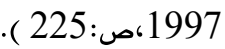

6.6. النظريات الاجتماعية والنفسية التي فسرت العدوان:

1.2.6 نظرية الإحباط-العدوان:-Frustration Aggression دائما عن الإحباط،وان وجود الإحباط يقود دائما إلى عدوان من نوع ما. ويعرف دولارد) (Dollard) وزملاءه الإحباط على انه"ما يحول دون استجابة متجهة نحو مدف ما، يكون قد ان اوانها في السلسلة السلوكية".

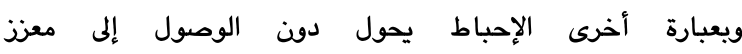
متوقع(مكفلين،ورتشارد غروس، 2002، صن: 77) وقد أشار دولارد (Dollard) إن استجابة العداء التي يستجيب لها الفرد ضد مصدر إحباطه بمثابة تفريغ لطاقته النفسية (محمود، 1995 ،ص:100)" إذ يعتبر السلوك العدواني في المواقف الإحباطية وسيلة فعالة للتغلب على العائق.(هرمز ويوسف، 1988، ص: 485 ). ويضيف دولارد (Dollard) ان ظهود الإحباط بسبب العدوان يتوقف على استعداد الشخص للعدوان وإدراكه لموقف الإحباط ,وقد لا يعتدي

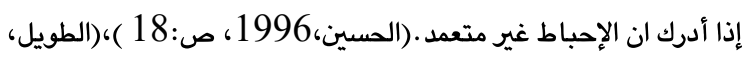

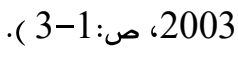
ويرى فيليب ماريمان (ph.Harriman) ,ان السلوك العدواني مو ) تعويض عن الإحباط المستمرووان كثافة العدوان تتناسب مع حجم الإحباط وكثافته.,رإذ كلما زاد إحباط الفرد زاد عدوانه. (العيسوي، 1993،ص:170 )

SOCIAL : 2.2.6 LEARNING THEORY يعد البرت باندورا (Bandura) أول من وضع أسس نظرية التعلم الاجتماعي او ما يعرف التعلم من خلال الملاحظة(يعقوب، باندور من 2002،ص: . 256 
لعينة مكون من 20 مراهق تترواح اعمارهم (18-16 ) وأشارت

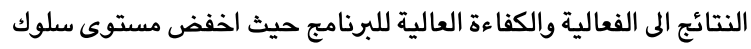
العنف لدى المجموعة التجريبي. 3.8. دراسة عبود وعبود (2003):

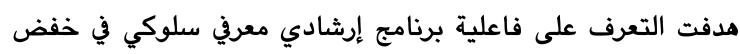

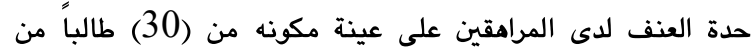

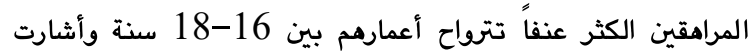

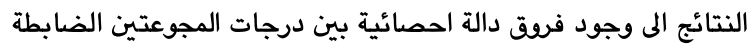

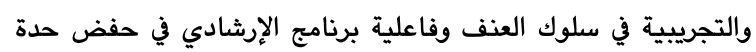

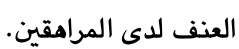

$$
\text { 4.8. دراسة الغنري (2004): }
$$

التي هدفت للكشف عن العلاقة بين العدوانية وبعض سمات الشخصية

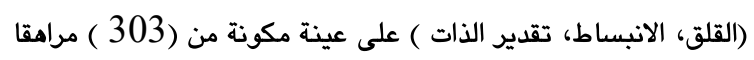

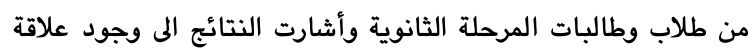
ارتباطة موجبة بين العدوانية ومستوى القلق لكل من الذكور والاناث الاأن العدوان عند الاناث يأخذ الشكل غير المباشرة ويميل للعنف العانف

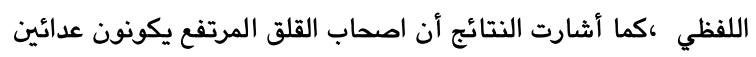

$$
\text { 5.8. - 5.8 دراسة لال (2006): }
$$

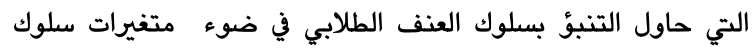
العدواني ودافعية الانجاز والصحة النفسية وتقدير الذات لعينة مكون من العناء

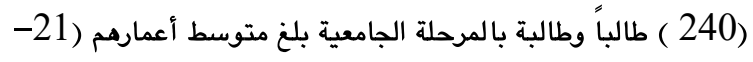
22 ) سنة وأشارت النتائج المى وجود علاقة ارتباطية بين العنف الطلابي

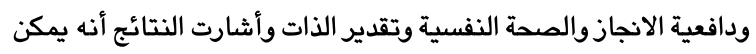
التنبؤ بالعنف الطلابي في ضوء المتغيرات الساتية والسابقة. 6.8. مناقشة دراسات سابقة:

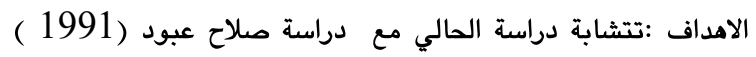
ودراسة عزب (2002) ودراسة عبود وعبود(2003 )في الاهداف وهو التعرف على فاعلية برنامج ارشادي في تخفيف السلوك العدوان، ولكنها

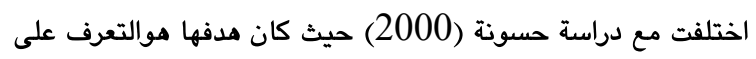
الاسباب لظاهرة العنف لدى الطلبةالددارس الثانوية، ومع دراسة الغنري

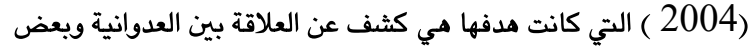

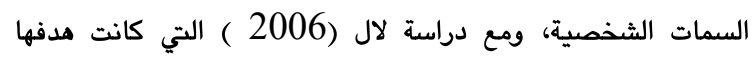
هوالتنبؤ بسلوك العنف الطلابي في ضوء متغيرات سلوك لات العات العدواني

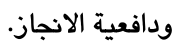
العينة: تتشابه الدراسة الحالي مع كل دراسات سابقة في ان العينة كانت الطلبة.
ودميج الأساليب والفنيات الإرشادية لتحقيق أفضل النتائج الارشاد

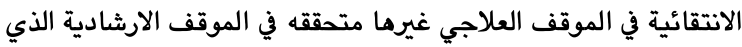

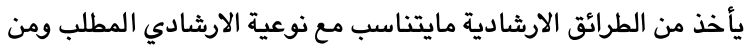

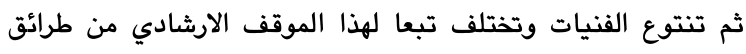

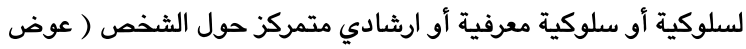
27: 2001، وتشير ادبيات الارشاد النفسي بأن الاتجاه الانتقائي الوظيفي التكاملي

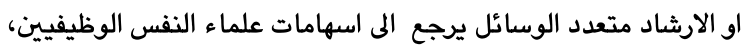
وعلى رأسهم وليم جيمس ،كما كان لاسهامات دولارد وميلر دوراً في هذا الاتجاه الا ان هذه الاتجاه ارتبط بفريدريك ثورن ولورانس بارمرو ودعم هذا الاتجاه ماقدمه لازاروس ومارت.

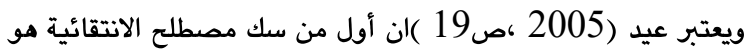

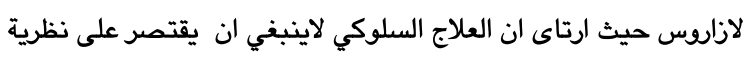

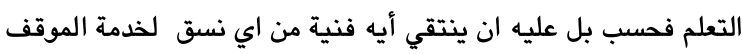

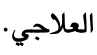

\section{8. دراسات سابقة حول سلوك العدواني}

1.8. دراسة صلاح عبود (1991):

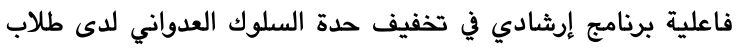
المرامقين ،هدفت الدراسة الى الكشف عن السلوك العدواني لدى الطلاب

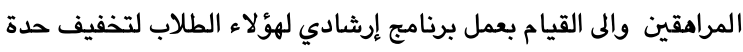

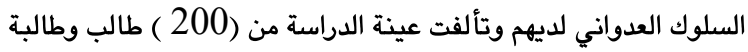

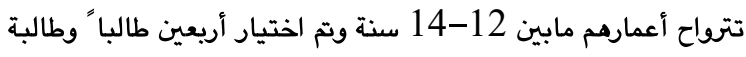
بطريقة عشوائية وتم تقسيمهم الى أريع مجموعات مجموعتان تجربيتيان ومجموعتان ضابطتان ،واستخدم مقياس السلوك العدواني واستمارة ملاحظة السلوك العدواني واستمارة دراسة الحالة وبرنامج إرشادي يقوم الحئان

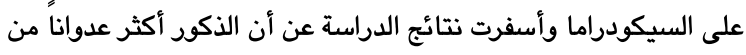

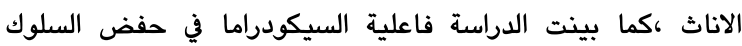
2.8. العدواني.

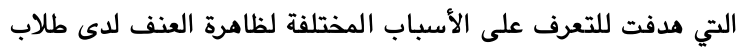

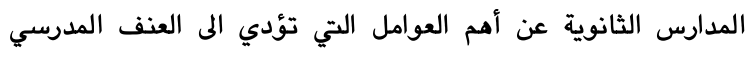

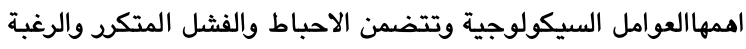
من تاكيد الذات والرغبة في السيطرة وجذب الانتباه والشعور بالملل

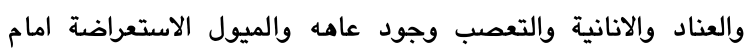
الجنس الاخر وغياب سلطة الوالدين والعوامل الاقتمادية مثل الفقر الإدان والبطالة وانتشار الافلام العنف وتدوال قصص العنف (عبدالله

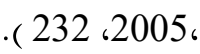

دراسة عزب (2002 ) التي هدفت للوقوف على فعالية برنامج علاجي تفاوضي تكاملي في التغلب على سلوكيات العنف لدى عينةالمرامقين 
والأخرى ضابطة، ولأجل الحصول على ماتين المجموعتين اختار الباحثين مدرسة رير سى وذلك للأسباب الآتية :1- - يتوافر فيها المكان المناسب لتطبيق مدرسية البرنامج الإرشادي.

$$
\text { 2- تعاون إدارة المدرسة مع الباحثين. }
$$

ويعد أن تم تحديد المدرسة ميدانياً للتجربة ،قام الباحثين بتطبيق أداة على طلبة المرحلة التاسعة فيها والبالغ عددهم (140 ) طالب، وهو اداة لقياس سلوك العدواني الذي ثم اعده من قبل الباحثين لأغراض

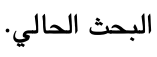

ويعد الاجابة عن اداة وتصحيح الإجابات ،رتبت درجاتهن من أعلى درجة الى أقل درجة، واختار الباحثين (20 ) طالب من الذين كانت درجاتهم هي الاعلى على السلوك العدواني ،ثم قام بتقسيم هذه العينة عشوائيا

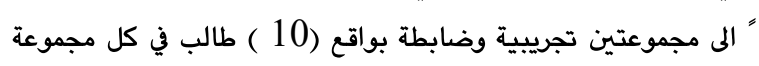

$$
\text { والجدول (1) يوضح ذلك. }
$$$$
\text { جدول رقم (1) يوضح عينة البحث }
$$

\begin{tabular}{|rrr|}
\hline المجاميع| & المجميع \\
\hline
\end{tabular}

اجراء الاختبار بعدي لمعرفة الفرق دلالاتها بين المجموعتين.

1.11 تكافؤ المجموعتين (الضابطة والتجريبية): إن توافر التكافؤ بين مجموعات البحث أمر ضصوي لتصميم البحث، إذ يسعى الباحثان إلى ان تكون مجموعة البحث متكافئة حتى لا تكون الفروق في أدائها راجعة إلى الفروق بين المجموعات أن أبو علام، 1989

1.11.1. التكافؤ في درجات مقياس سلوك العدوان في الاختبار القبلي: للتحقق من تكافؤ المجموعتين على متغير درجات الطلبة على مقياس سلوك العدوان تم استعمال اختبار (مان - وتتني) للعينات صغيرة الحجم لمعرفة دلالة الفرق بين متوسط رتب العينة عند هذا المتغير، إذ تبين ان القيمة المحسوية تساوي (43) وهي غير دالة عند مستوى (0.05) لانها أكبر من القيمة الجدولية البالغة (23)، ويذلك لم

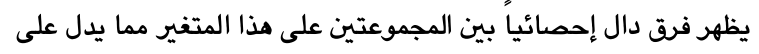
ان المجموعتان متكافئتان والجدول (2) يوضح ذلك.
النتائج :تشابه الدراسة الحالي مع دراسة صلاح عبود (1991) ودراسة عزب (2002 ) ودراسة عبودوعبود (2003 ) في فاعلية برنامج ارشادي في خفض حدة العنف لدى الطلبة 9. - 9جتمع البحث

يضم طلبة المرحلة التاسعة في مرحلة التعليم الاساسي لمدراس الذكور فقط في الجهة الغربية في مركز محافظة دهوك.

\section{0. عينة البحث}

أن طبيعة البحث تتطلب توافر مجموعتين من طلبة المرحلة التاسعة إحداهما تجريبية تخضع للبرنامج الإرشادي لتخفيف سلوك العدواني،

\section{1. التصميم التجريبي}

اعتمد الباحثين على المنهج التجريبي ،ولأجل تحقيق هدف البحث وفرضيتة استعمل الباحثين تصميم المجموعات المتكافئة التي احداها تجريبية والاخرى ضابطة ذات الاختبار القبلي والبعدي (عبد الحفيط و باهي ،2000 ،ص 117 ). ولغرض اختبار فرصية البحث الحالي استخدام الباحثين التصميم التجريبي ذا التطبيق البعدي، وقد صمم

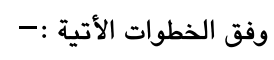

اختيار (20) طالب كعينة لموضوع البحث الذين حصلوا على اعلى الدرجات بعد اجراء الاختبار القبلي.

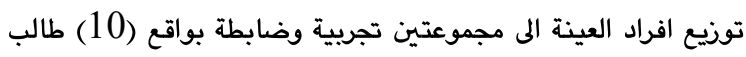
لمجموعة التجربية ويواقع (10) طالب لمجموعة ضابطة بعد أن تم تكافئهم وفقا لعدد من المتغيرات.

\begin{tabular}{|c|c|c|c|c|c|c|c|c|c|}
\hline \multirow[t]{2}{*}{ مستوى الدلالة 0.05} & \multicolumn{2}{|c|}{ مان - وتني } & \multirow{2}{*}{ متوسط } & \multirow{2}{*}{ الرتب } & \multirow{2}{*}{ الانحراف } & \multirow{2}{*}{ الحسابي } & \multirow[t]{2}{*}{ 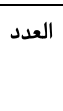 } & \multirow[t]{2}{*}{ المجموعة } & \multirow[t]{2}{*}{ المتفير } \\
\hline & الجدولية & المحسوية & & & & & & & \\
\hline \multirow[t]{2}{*}{ غير دالة } & 23 & 43 & 9,80 & 98 & 26,440 & 73,80 & 10 & التجريبية & الإختبار \\
\hline & & & 11,20 & 112 & 16,471 & 77,20 & 10 & الضابطة & القبلي \\
\hline
\end{tabular}
استخدام البرنامج الإرشادي الانتقايي كمتغير مستقل مع المجموعة التجريبية في حين لم يتعرض المجموعة الضابطة الى لاي برنامج. جدول ( 2) قيمة (مان- ويتني) لمتغير درجات أفراد المجموعتين الضابطة و التجريبية

استخدام الباحثان اختبار (مان - وتني) للعينات صغيرة الحجم، وتبين ان قيمة (مان - وتني) المحسوية تساوي (37) وهي غير دالة لانها اكبر
2.1.11. التكافؤ في متغير العمر الزمني بالسنوات: لمعرفة دلالة

الفرق بين متوسط رتب اعمار المجموعتين (التجريبية - والضابطة) 
من الجدولية البالغة (23) عند مستوى (0.05)، وبذلك لم يظهر فرق دال احصائياً بين المجموعتين في هذا المتغير مما يدل على ان اندان المجموعتين متكافئتان والجدول (3) يوضح ذلك.

\begin{tabular}{|c|c|c|c|c|c|c|c|c|c|}
\hline مستى & & قيمة مان- & 3. & q. & & & & & \\
\hline الدلالة 0.05 & الجدولية & المسوبة & $\frac{-1}{3}$ & $\frac{2}{3}$ & $\begin{array}{c}3 \\
9 \\
9 \\
y_{1}\end{array}$ & $\frac{3}{j}$ & العدد & المجموعة & المتغير \\
\hline \multirow{2}{*}{ غير دالة } & \multirow[t]{2}{*}{23} & \multirow[t]{2}{*}{37} & 9,20 & 92 & 0,823 & 21,70 & 10 & التجريبية & العمر الزمني \\
\hline & & & 11,8 & 118 & 0,876 & 22,10 & 10 & الضابطة & بالسنوات \\
\hline
\end{tabular}

المحسوبة تساوي (0,447)، وهي اصغر من القيمة الجدولية البالغة (1,36) عند مستوى دلالة ( 0,05 ) ويذلك لم يظهر فرق دال إحصائياً بين المجموعتين في هذا المتغير مما يدل على اند ان المجموعتين 3.1.11. التكافؤ في متغير المستوى الإقتصادي: لمعرفة دلالة الفرق في متغير المستوى الإقتصادي لأفراد المجموعتين التجريبية متكافئتان والجدول(4 ) يوضح ذلك.

والضابطة استعمل اختبار (كولموجرف - سميرنوف) وتبين ان القيمة جدول ( 4)قيمة كولموجرف - سميرنوف لمتغير المستوى الإقتصادي لأفراد المجموعتين الضابطة والتجريبية

\begin{tabular}{|c|c|c|c|c|c|c|c|c|c|}
\hline \multirow{2}{*}{ الدلالة مستوى 0.05} & \multicolumn{2}{|c|}{ قيمة K سميرونوف } & \multicolumn{4}{|c|}{ المستوى الإقتصادي } & \multirow[b]{2}{*}{ 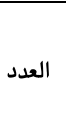 } & \multirow[b]{2}{*}{ المجموعة } & \multirow[b]{2}{*}{ المتغير } \\
\hline & الجدولية & المسوبة & جيد جداً & جيد & متوسط & ضعيف & & & \\
\hline \multirow[t]{2}{*}{ غير دالة } & 1,36 & 0,447 & 4 & 3 & 2 & 1 & 10 & التجريبية & \multirow{2}{*}{ الاقتصاي } \\
\hline & & & 2 & 4 & 2 & 2 & 10 & الضابطة & \\
\hline
\end{tabular}

الاستعمال والذي يعده بعضهم صدقا" للمحتوى، لأن الخبير يلاحظ

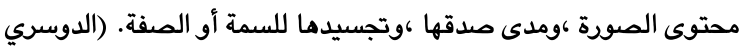
،1985، ص: 85 ) معليه عرض الباحثين الأداة بصورتها الأولية على مجموعة من الخبراء والمختصين في أقسام العلوم التربوية والنفسية في جامعة دهوك. وطلبت منهم ابداء آرائهم في صلاحية كل فقرة للأداة لقياس السلوك العدواني، ويعد استخدم مربع كاي وسيلة إحصائية للكشف عن دلالة الفرقق بين آراء الموافقين وغير الموافقين من الخبراء ،وتم قبول (42 )فقرة من أصل (44 ) في الأداة مع إجراء

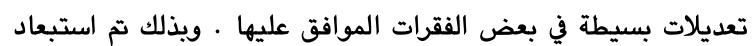
الفقرتين المرقمتين (26-16 ) اللتين لم تحظيا بنسبة اتفاق بين الخبراء (80 ٪ ) الملحق رقم (1)، ثم قام الباحثين بترجمة الأداة المكونة من 42 فقرة والتعليمات الخاصة بكيفية الإجابة الى اللغة الكوردية وتحقق صدق الترجمة عن طريق عرض النسخة العربية والكوردية على ثلاثة من خبراء من المتخصصين في العلوم التربوية واللغة وفي ضوء آرائهم تم تعديل بعض المصطلحات.

3.12. ثبات الأداة: الثبات مو الاتساق في أداء الأفراد والاتساق بالنتائج عبر الزمن، والأداة الثابتة هي الأداة التي تعطي النتائج نفسها اذا طبقت على المجموعة

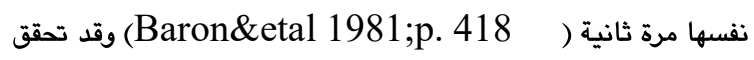
الباحثين من ثبات أداة سلوك العدواني من خلال استخدامها لأسلوب التجزئة النصفية لاستخراج معامل ثبات الأداة فبعد أن طبقت الأداة

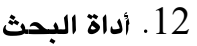

أطلع الباحثين على بعض الأدبيات التي تناولت متغير سلوك العدواني ،وكذلك الإجراءات المعتمدة في بعض الدراسات السابقة في هذا المجال له بهدف الاستفادة من تلك المقاييس التي استخدمها الباحثون في قياس سلوك العدواني. وتمت صياغة الفقرات المكونة للأداة بصورتها الأولية وقد بلغ عددما (44) فقرة وأمام كل فقرة ثلاثة بدائل وهي (تنطبق علي، متردد، لاتنطبق علي ) · و يتكون من ثلاثة مجالات وهو مجال (العدوان نحو

الذات )و (العدوان نحو الاخرين )و(العدوان نحو الممتلكات العامة ).

1.12. تصحيح الأداة:

ويقصد به وضع درجة على استجابة المفحوص على لكل فقرة من فقرات اداة ومن ثم جمع هذه الدرجات لايجاد الدرجة الكلية لكل استمارة، ولكون فقرات أداة مقسمة على فقرات ايجابية وفقرات سلبية وقد اعطيت للفقرات ايجابية اوذان (1-2-3 ) وأعطيت (3) للبدائل تنطبق علي و(2) للبدائل متردد و(1) للبدائل لاتنطبق علي، وتعكس الدرجات في حالة الفقرات السلبية.

2.12. - 2.12 صدق الأداة: فالأداة الصادقة هي الأداة التي تقيس ما وضعت من أجلها بشكل جيد (علام ،02004ص:1904 )وقد تحقق الباحثين من صدق الأداة من خلال الاعتماد على الصدق الظاهري باعتباره من أنواع الصدق الشائعة من هلئ 
1.14. تصديد الاحتياجات: في هذه الخطوة قام الباحثين بتحديد احتياجات المجموعة المراد تقديم الخدمات إليها، والتي تعد حجر الأساس في عملية التخطيط، واعتمد الباحثين في ذلك على عدد من المعطيات التي تمثل جوانب الحصول على المعلومات المهمة في تدقيق مذا الغرض وعليها تمت صياغة

موضوعات الجلسات الإرشادية في البرنامج وعلى النحو الأتي :

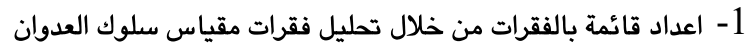
الذي اعده الباحثين وذلك لتصديد مايقابل من الحاجات الإرشادية لان

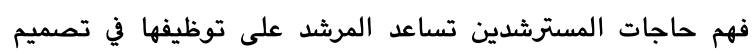

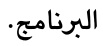
2- نتائج مقياس سلوك العدوان الذي تطبق على عينة التجربة وبعد

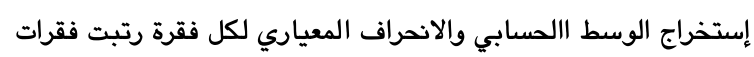
تصاعدي لمعرفة حاجات المجموعة.

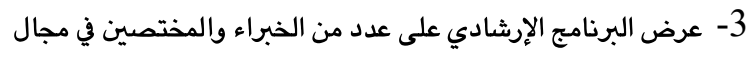

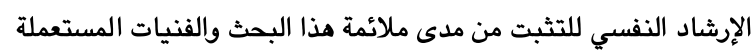
والزمن الذي يستغرقه البرنامج لتحقيق اهدافه. 2.14. تحديد الأولويات: عتمد الباحثين ترتيب الاحتياجات او الموضوعات الإشادية حسب الاوليات

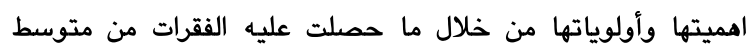

$$
\text { حسابي وانحراف المعياري. }
$$

3.14. تدديد الاهداف العامة والخاصة والسلوكية:

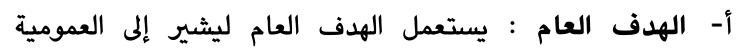

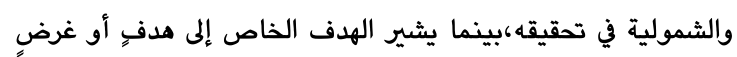

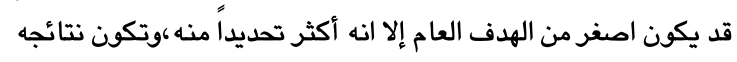

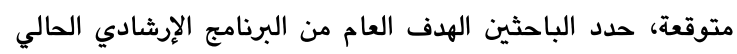

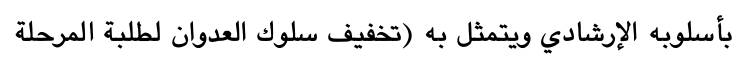

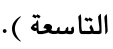

ب- الهدف الخاص: وهوما يسمى بالاهداف التعليمية أو الضمنية

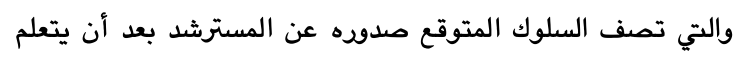

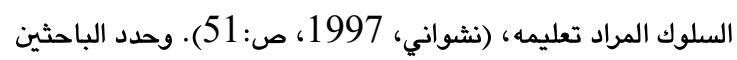

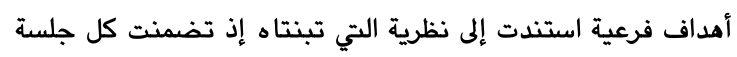
مجموعة من الأهداف الخاصة متساوقة مع طبيعة المشكلة والنظرية المعتمدة والنشاطات المستخدمة أو المستعملة فيها.

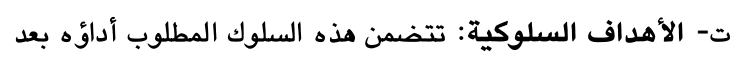
الانتهاء من كل جلسة إرشادية، وذلك من خلال التحديد الدقيق لهذا

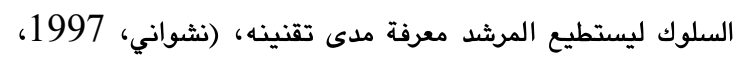
ص:56). كما أن هذه الأهداف تكون إجرائية قابلة للقياس المراني والملاحظة.
على عينة مكونة من (60) طالب تم اختيارمم بطريقة عشوائية من بين طلبة المرحلة التاسعة في مدرسة كاروان للبنين. قام بحساب درجات كل

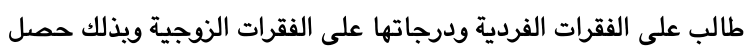
على قائمتين للدرجات تمثل درجات الطلبة على النصف الأول من الأداة (الفقرات الفردية ) وتمثل الثانية درجاتهم على النصف الثاني من الأداة (الفقرات الزوجية )، وبعد ذلك استخدم معامل ارتباط بيرسون وسيلة

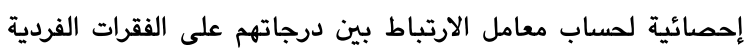

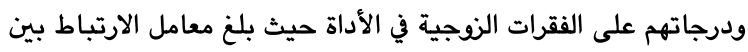
نصفي الأداة (0.76 ) لما كانت قيمة الارتباط المحسوية تمثل ثبات

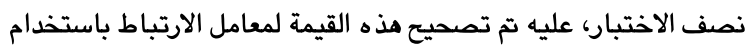
معادلة سبيرمان - بروان التصحيحية، فتبين ان قيمة معامل الثبات

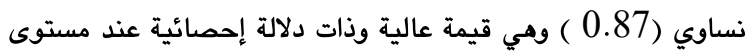
(0.05) (0.05) وتشير الى ثبات الأداة.

\section{3. - الوسائل الإحصائية}

1- مان وتني التحقيق من صدق الفرضية للأختبارين البعدين والتحقق

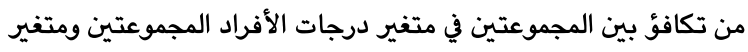
العر. 2- معامل ارتباط بيرسون ومعادلة سبيرمان -بروان التصحيحة في

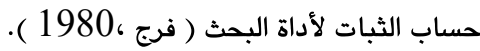

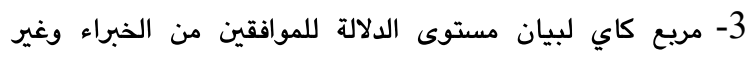

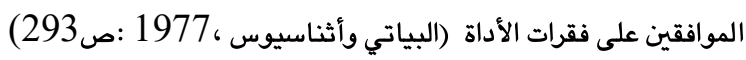
*تألفت لجنة الخبراء المتتخصصين من السادة المدرجة أسماؤهم

$$
\begin{aligned}
& \text { 1- د.فاتح ابلد فتوح - استاذ } \\
& \text { 2- د. محمد سعيد محمد - استاذ مساعد }
\end{aligned}
$$

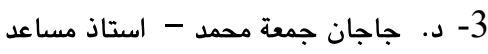

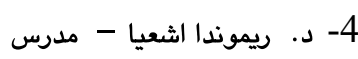

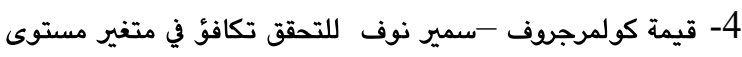

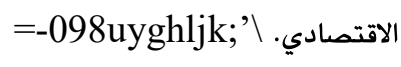

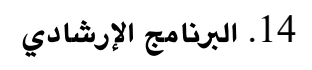

البرنامج الإرشادي على أساس أسلوبي الإرشاد الانتقائي وفق نظام

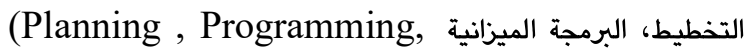
:Budgeting System)

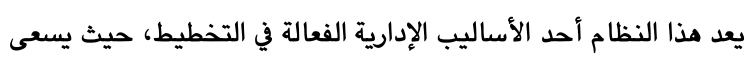

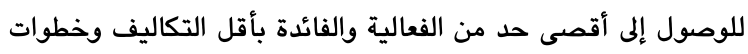
التخطيط لبرنامج التوجيه والإرشاد. 
ككرسي خالي التدريب البيتي. وتم تطبيق البرنامج الإرشادية بتداً من يوم السبت المصادف $2015 / 3 / 2$

حيث قام احد من الباحثين بتطبيق كل الجلسة ارشادية كمرثد مع مجموعة تجريبية. المحاضر و المناقشات الجماعية : يعد من الاساليب الهامة في كل النظريات النفسسية وتأخذ طابع التفاعل المنظم في مواقف الارشادي وتعليمي تعاوني مشترك، يتيح للأعضاء المجموعة الإرشادية فرصة للتعبير عن ذواتهم ومشاعرمم وأفكارمم ومشكلاتهم النمذجة : تعد فنية إرشادية تنتمي الى نظرية التعلم الاجتماعي التي جاء بها باندورا ولتي يعرف كذلك بالتعلم بالملاحظة. ( سعفان إنتيه

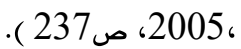

لعب الدور: يعد من الأساليب الإرشادية النفسية المستخدمة في النظريات السلوكية المعرفية وتبني اسلوب لعب الدود لنظرية باندودا في التعلم الاجتماعي. التنفيس الانفعالي: من الاساليب النفسية التي تنتمي للاتجاه

التحليلي وتكتسب أهمية خاصة في نظرية فرويد التحليلة النفسية.

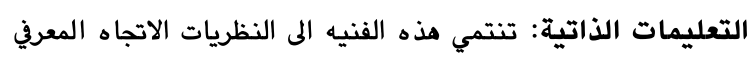

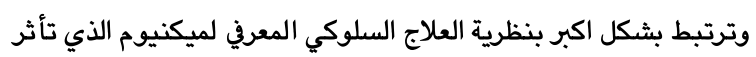
بما قدمه بيك وما أشار اليه اليس حول الاحاديث الذاتية السلبية ودورها

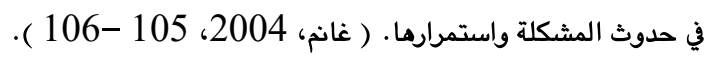
الضبط الذاتي: يعد الضبط الذاتي (التحكم الذاتي )من الاساليب النفسية السلوكية المعرفية ويمثل الجهد الذاتي يبذله الفرد والفعالية الواعية المقصود التي يقوم بها في مواجهة المواقف. الاسترخاء: تنتمي الى فنيات الاتجاه السلوكي يتم فيها تدريب المسترشد على تحقيق الهدوء والارتخاء وتحقيق التوانن الجسمي.

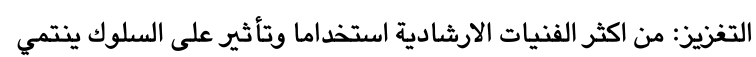
الى الارشاد السلوكي. ( الخطيب، 1989، صن 281 ). التقويم الذاتي تنتمي الى النظرية الواقعية لوليم جلاسر تتلخص في مساعدة عضو المجموعة الارشادية ودعوته الواعية والمنظمة لاجراء تقويم لسلوكه الشخصي والحكم عليه. التخطيط للسلوك المسئوول: من الأساليب الفنية التي تنتمي النظرية الواقعية ويعتبر جلاسر التخطيط للسلوك المسئوول والقواعد

$$
\text { التي يقوم عليها الارشاد الواقعي. }
$$

التحدث الى كرسي خالي: احدى فنيات الارشادية التي ترتبط من الأساليب الإرشادية المستخدمة في نظرية ادلر الإرشادية حيث يساعد الدي

$$
\text { المسترشد على اعادة توجيه نفسه. }
$$

التدريب البيتي: يعد من الأساليب الإرثادية الهامة في معظم النظريات

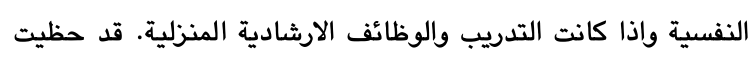

4.14. تحديد النشاطات والفعاليات ذات العلاقة بأهداف البرنامج الإرشادي قام الباحثين باختيار النشاطات والفعاليات ذات العلاقة بأهداف البرنامج الإرثادي وعليه حددت الرابعة عشر جلسة إرشادية وبواقع جلستين أسبوعياً، كما أن الزمن المستغرق في عقد الجلسات (45) دقيقة في أعلى تقدير.

$$
\text { 15. تقويم النتائج }
$$

إن الغرض الأساس من التقويم هو الحصول على المعلومات اللازمة، فيما إذا كان البرنامج الإرشادي قد استطاع أن يحقق الأهداف

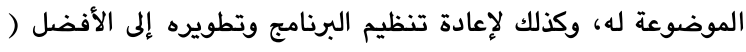

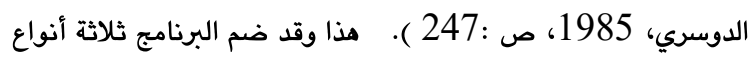
من التقويم هي أ- التقويم التمهيدي : يتمثل بالإجراءات التي قام به الباحثين قبل تطبيق البرنامج الإرشادي متمثلة بإجراءات الصدق الظامري للبرنامج وذلك بعرض البرنامج على مجموعة من الخبراء. كما أن الن التقويم التمهيدي قد تمثل في إجراءات توزيع العينات بطريقة متكافئة، وكذلك تحديد الحاجات على وفق ما حصلت عليه الفقرات من درجات باستخراج المتوسط الصسابي والانحراف المعياري لبيان حدة

$$
\text { المشكلة وإجراءات الاختبار القبلي. }
$$

ب- التقويم البنائي : وهو عملية ترافق الجلسات الإرشادية، إذ يتم طرح الأسئلة التي تتعلق بموضوع الجلسة الإرشادية ومناقشة إجابات أفراد المجموعة التجريبية، كما انه يتضمن الاستماع إلى آراء ومقترحات أفراد المجموعة تجريبة حول كل ما يدود أثناء الجلسات. ت- التقويم النهائي : يتمثل بتطبيق مقياس سلوك العدوان في نهاية البرنامج الإرشادي على المجموعتين ( المجموعة التجريبية والمجموعة الضابطة ) وذلك لمعرفة التغيرات التي من المحتمل أن تطرأ على الِى درجات المجموعة التجريبية مقارنة بالمجموعة الضابطة. تحقيق أهداف البحث الحالي اتبع الباحثين اسلوب إرثادية وهو الأنتقائي والذي يضم عدداً من النظريات لتكون الممارسة الإرثادية المنظمة والمتناسقة تخطيطاً وتنفيذاً. *تألفت لجنة الخبراء المتتخصصين من السادة المدرجة أسماؤهم

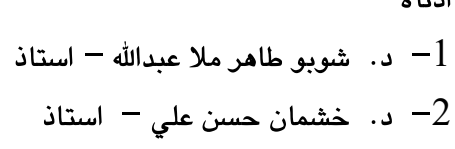

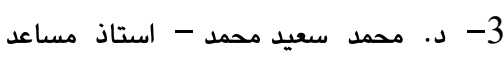
وتقييماً والمستمدة من الاتجاة الانتقائي التكاملي، والأساليب وفنيات إرشادية متنوعة وهي المحاضرات والمناقشات الجماعية ،النمذجة ،لعب الدود ،التنفيس الانفعالي ،التعليمات الذاتية ،الضبط الذاتي، الاسترخاء، التقويم الذاتي، التعزيز، التخطيط للسلوك المسئول 
13- الجلسة الثالثة عشر : من أجل حياة خالية من العنف.

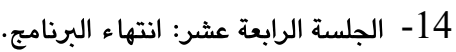

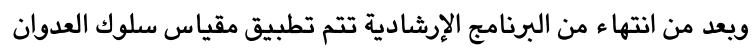

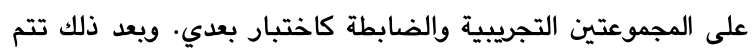
تحليل النتائج وتفسيرها على وفق اهداف البحث وللتحق من صحة الفرضية :-

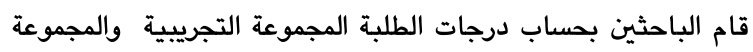
الضابطة على مقياس سلوك العدوان الذي طبق بعد انتهاء البرنامج ثم دمبات رتبت درجات الطلبة المجموعتين وحسبت قيمة مان - وتني لعينتين مستقلتين (متوسطتي الحجم )تبين وجود فرقق دالة إحصائيا لان قيمة

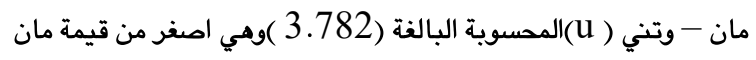

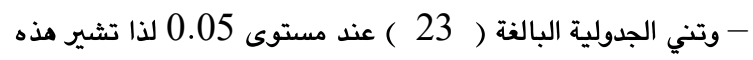

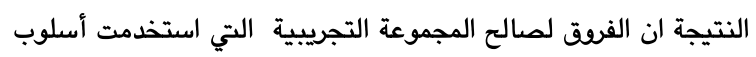
الإرشادي الانتقائي والجد ول( 2 ) يوضح ذلك.
باهتمام كبير في كل نظريات المتمركز حول الذات الا انها لاتقل أهمية عن باقي عن النظريات.

وكانت عناوين الجلسات الإرشادية هي :1- الجلسة الأولى :الافتناحية التهيئة للبرنامج الإرشادية. 2- الجلسة الثانية :الممارسات العنيفة والتهيئة للسيكودراما. 3- الجلسة الثالثة : الحكم الذاتي على السلوك. 4- الجلسة الرابعة : التدريب على الاسترخاء. 5- الجلسة الخامسة : التحكم ضبط الذات. 6- الجلسة السادسة : المراقبة الذاتية والتقويم الذاتي . 7- الجلسة السابعة :التدريب على المهارات الاجتماعية. 8- الجلسة الثامنة : مهارات التسامح والتحرك الايجابي. 9- الجلسة التاسعة :مهارات التواصل العقلي مع الاخرين.

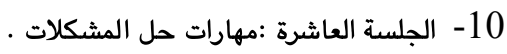
11- 11- الجلسة الحادية عشر : المسؤولية واتخاذ القرارات . 12-الجلسة الثانية عشر:التخطيط للسلوك المسؤول سلوكيات اللباقة

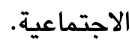
جدول (5): قيمة مان وتني في الاختبار البعدي لمقياس سلوك عدوان بين المجموعتين التجريبية والضابطة

\begin{tabular}{|c|c|c|c|c|c|c|c|}
\hline \multirow{2}{*}{ مستوى الدلالة } & \multicolumn{2}{|c|}{ قيمة مان وتني } & \multirow{2}{*}{ متوسط الرتب } & \multirow{2}{*}{ مجموع الرتب } & \multirow{2}{*}{ العدد الع } & \multirow{2}{*}{ المقارنة } & \multirow{2}{*}{ المتغير } \\
\hline & الجدولية & المحسوبة & & & & & \\
\hline دالة لصالح & \multirow[b]{2}{*}{23} & \multirow[b]{2}{*}{3.782} & 15.50 & 155.00 & 10 & التجريبية & \multirow{2}{*}{ الاختبار } \\
\hline التجريبية & & & 5.50 & 55.00 & 10 & الضابطة & \\
\hline
\end{tabular}

أسفرت النتائج، عن فاعلية البرنامج الإرشادي على وفق أسلوب ص10)، وهذا يتفق مع معظم الدراسات التي تعتمد البرامج الإرشادية

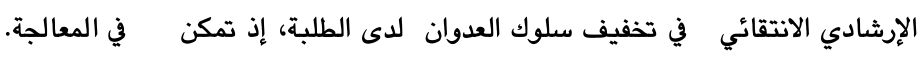

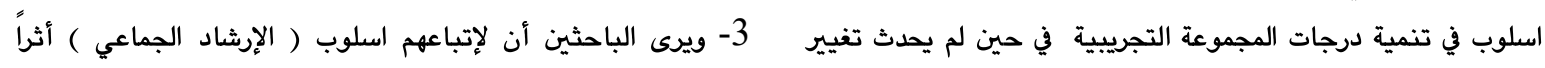

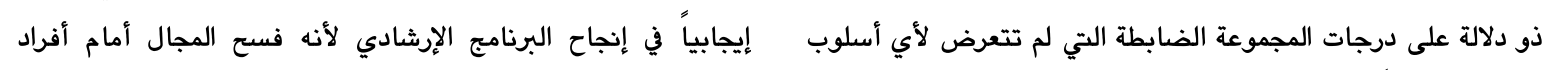

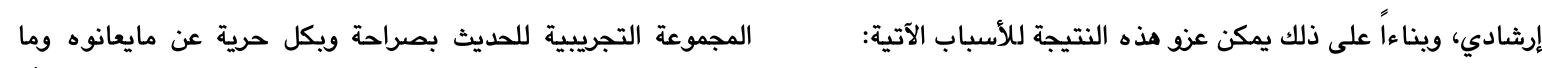

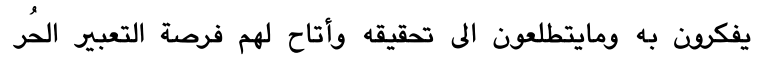

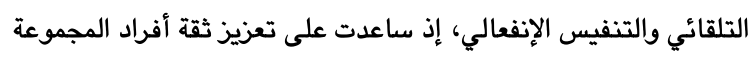

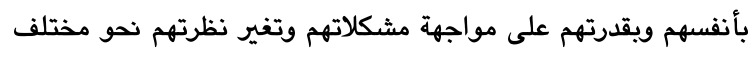

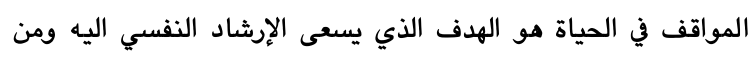
خلال برامجه الى تحقيقه. 16. التوصيات 1- الافادة من البرنامج الذي استخدام في هذه الدراسة من قبل الوحدات الإرشادية في جامعات الاقليم. - الإن. 2- العمل على توفير فريق متخصص بالإرشاد الإلم في جميع المدارس الاقليم. 3- تفعيل الأنشطة اللامنهجية كالرياضة والألعاب الترفيهية الباعث

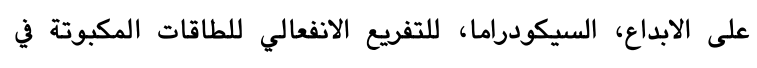

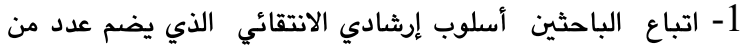

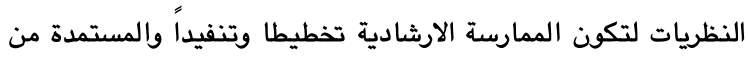

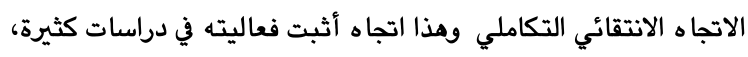

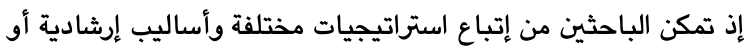
علاجية كثيرة، فالمبدأ الأساس الذي يقوم عليه هذا الاتجاه هو الاهتمام التام التانيا

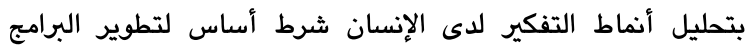

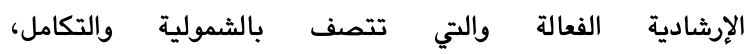
(Ollendick and Cern 1983 ,P.115) 2- كان للعلاقة الإرشادية الإيجابية بين احد من الباحثين والطلبة

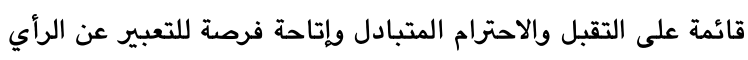

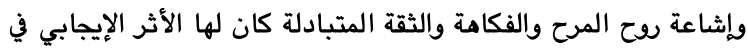

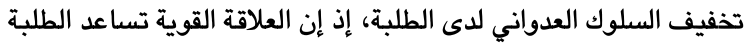

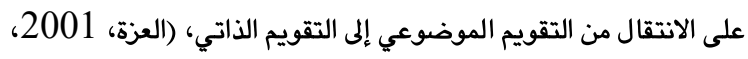




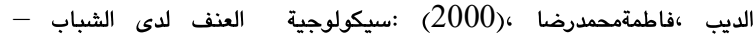
دراسة|مبيريقية في العلاقة بين الأساليب الوالدية في التنشئة الاجتماعية

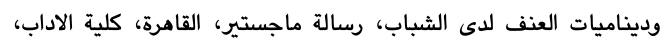
جامعة عين شمس. دافيدوف، لندل ،( 1993 ) : : مدخل علم النفس، ترجمة سيد الطواب وآخرون، أرئ، الرياض، دار المريخ. راشد، عدنان غائب، (2002 ) : سيكولوجية الطفولة، دار وائل، للنشر والتوزيع، عمان. الزغبي، أحمد محمد ،( 1997 ) : السلوك العدواني عند الاطفال، كيف نفهمه، مجلة

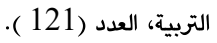

سعفان، محمد احمد ابراهيم ،(2005 ): العملية الارشادية، الطبعة الأولى ،دار الكتاب (12) )

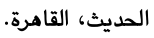
الشريف،محمد يوسف،(1999):مظاهر العدوان ومستوى القلق لدى الشباب

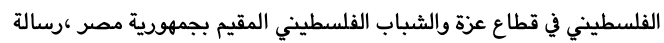

غير منشورة ،كلية الاداب ،قسم علم النفس ،جامعة الزقازيق ،مصر.

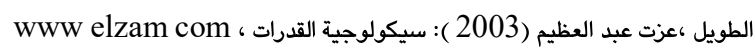
/ aggression. عبدالله، معتز سيد، (2005 ) : العنف في الحياة الجامعية، مركز البحوث والدراسات. النفسية ،كلية الاداب، جامعة القاهرة.

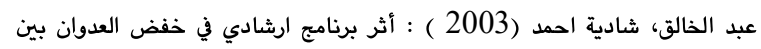

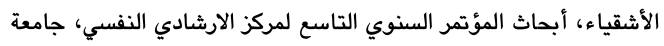

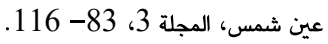
عبد الحفيظ، اخلاص محمد وياهي ،مصطفى حسن، (2000 ) : طرق البحث العلمي

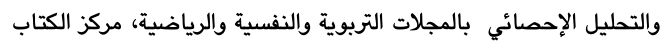
للنشر والتوزيع، القاهرة.

عبد المعطي، حسن مصطفى ‘( 2001 ) ): الاضطرابات النفسية في الطفولة والمرامقة الاسباب - التشخيص - العلاج، القاهرة، مكتبة القاهرة للكتاب.

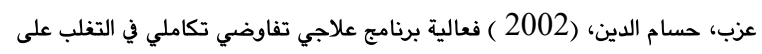

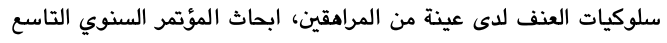

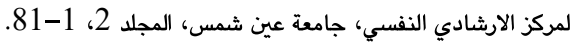

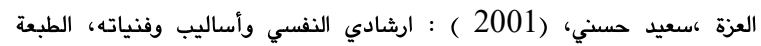
السادسة، الدار العلمية الدولية للنشر والتوزيع، عمان.

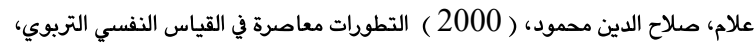
ط2، مطابع القبس التجارية.

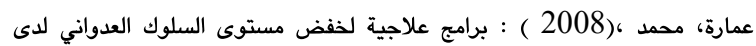
المرامقين، الاسكندرية، المكتب الجامعي الحديث.

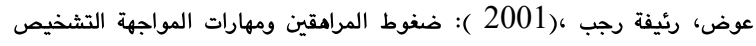
العلاج، القاهرة ،مكتبة النهضة المصرية.

العيسوي، عبد الرحمن ،(2005 ) : المشكلات السلوكية في الطفولة والمراهقة ،بيرت الفهرة ،

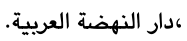

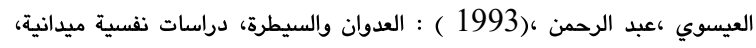
القاهرة، الدار الجامعية. عارف، نجوى عبد الجليل، (2003 ) : برنامج ارشادي مقترح لتحسين التواصل اللفظي بين الأنواج، مجلة الارشاد النفسي، جامعة عين شمس، العدد 17 ، 17 $280-247$ ،

عذاب ،نشعة كريم، ورضا، كاظم كريم ‘(2011 ، 240 : برامج الارشاد النفسي مفهومها وخطوات بنائها، ط1، دار الكتب الوثائق، بغداد.
داخلهم، وتنمية اجسامهم وعقولهم كي يتمكنوا من الشعور بالراحة النفسية والطمانينة داخل المدرسة. 4- تفعيل دور مجالس الاباء ومشاركتهم في خطط المدرسة الارثادية والنفسية التي تسامم في حل الكثير من الازمات الطلبة. 17. المقترحات

1- أثر برنامج ارثادي انتقائي في تخفيف الضغوط النفسية لدى

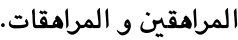

2- أثر برنامج ارشادي باللعب الجماعي لتخفيف الممارسات العنيفة للأطفال والمرامقين.

3- أثر برنامج ارشادي اسري في تخفيف الممارسات العنيفة للأنباء.

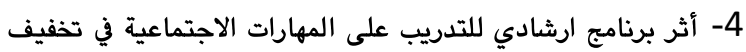
الممارسات العنيفة للأطفال والمرامقين.

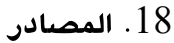

أسعد، ميخائيل ومالك مخول (1982 ) : مشكلات الطفولة والمرامقة، منشورات دار أفاق جديدة، بيوت.

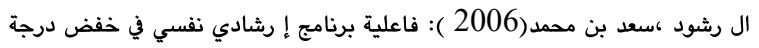

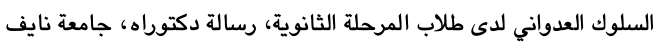

العربية للعلوم الأمنية الرياض. لدئ.

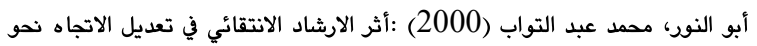

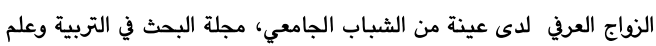

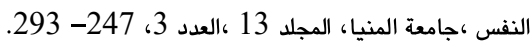

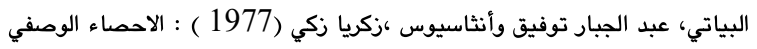
والاستدلالي في التربية وعلم التربية، مطبعة العمال المركزية ،بغداد.

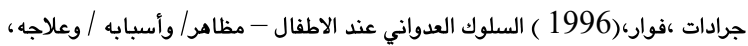
رسالة المعلم المجلد (37 )، العدد الرابع، وذارة التربية والتعليم، عمان.

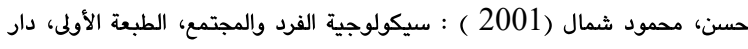
الافاق العربية.

حجازي، نسرين رشيد (1988 ) : أساليب الأمهات في التعامل مع الأنماط السلوكية

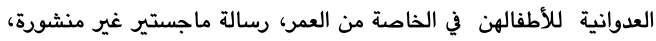

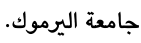
الخطيب ،جمال (1987 ): تعديل السلوك والقوانين والاجراءات ،الطبعة الأولى كمان. الخطيب، محمد جواد، (1989 ) : العلاقة بين مستوى القلق والتحصيل الدراسي

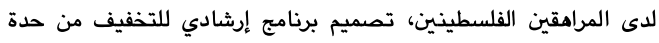

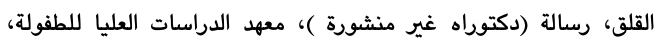
جامعة عين شمس، القاهرة ،مصر.

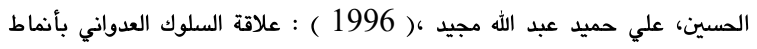

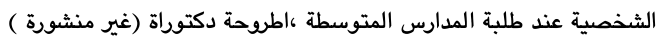
جامعة بغداد، كلية التربية. الخفاجي، زينب حياوي بديوي (1994 ) : قياس الأمن النفسي لموظفي وموظفات

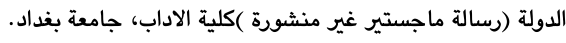

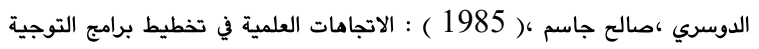
والارشاد، مجلة رسالة الخليج العربي / العدد 15، الرياض، السعودية. 
السنوي الحادي لمركز الارشاد النفسي ،جامعة عين شمس، المجلد 6 .542-59،

ملحم، سامي محمد،(2004 ) : علم نفس النمو ، الطبعة الأولى، دار الفكر للنشر

$$
\text { والتوزيع، عمان. }
$$

نشواني، عبد الحميد، (1997) : علم النفس التربوي، الطبقة الأولى، مؤسسة الرسالة للطباعة والنشر، عمان.

هرمز، صباح حنا ويوسف حنا ابراهيم (1988 ) : علم نفس التكويني للطفل، مؤسسه الرسالة، دار عمار مالأردن.

يعقوب، نايف ناخذ رشيد ،(2002 ): مركز الضبط وعلاقته بالسلوك العدواني لدى الدار

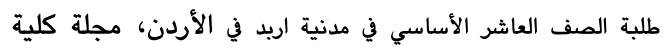

التربية، جامعة طنطا، المجلد الأول، العدد (31 ) .

Beron,R\& Other (1981 ) :psgchology Understanding Begavior.Tokyol Holt\& Senders intemational.

Mummedey, (1988 ); A,Aggressive behavior. In Hewton,M.and etal. (ed.s) introduction to social psychohogy ;Eurbean perspective Cambridge;Basil black Well, LTD.P.266.

Ollendick T.H. and cerny ,J,A (1983) clinical behavior therapg With chidren ( Applied psychology) Plenun press $1 \mathrm{Ed}$.
عليان، فؤاد ،(2004 ) :موسوعة فن التعامل مع المرامقين والمرامقات، الطبعة الاولى، دار صفاء للطباعة والنشر والتوزيع ،عمان.

عبد الستار، ابراميم ،(1994 ) : العلاج النفسي السلوكي المعري الديث، أساليبيه وميادين تطبيقه، القاهرة، دار الفجر للنشر والتوزيع.

غنمية ،هناء احمد ،(2004 ):العنف نحو الزوجة وعلاقة بالسلوك العدواني للأنباء

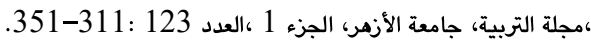

غانم ،محمد حسن ،(2003 ) : العلاج النفسي السلوكي، المكتبة المصرية، الأرهن،

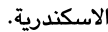
فرج، صفوت ،(1980) : القياس النفسي، دار الفكر العربي، القاهرة.

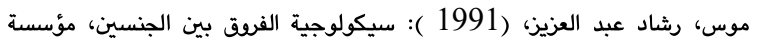
مختارة، دار عالم المعرفة، القاهرة ،مصر.

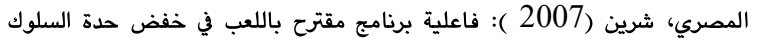

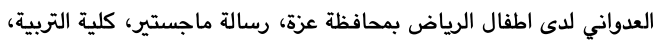
البرنامج المشترك بين جامعة الأقصى وعين شمس، عزة.

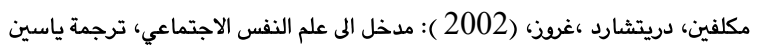
حداد، الطبعة الأولى، دار وائل للنشر، بغداد.

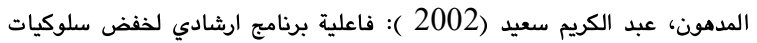

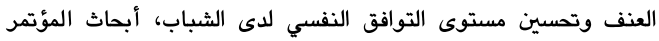


محلق رقم 1: المقياس بصيغته النهائية

\begin{tabular}{|c|c|c|c|c|}
\hline لا تنطبق علي & 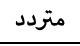 & تنطبق علي & 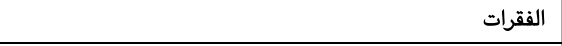 & 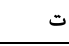 \\
\hline & & & أتعصب بشدة لرأيي. & -1 \\
\hline & & & أضرب نفسي عند الغضب. & -2 \\
\hline & & & أميل الى الخشونة عندما العب مع زملائي. & -3 \\
\hline & & & أحرض زملائي على الفوضي داخل الصف. & -4 \\
\hline & & & عندما اخرج من الصف أغلق الباب بعنف. & -5 \\
\hline & & & أنثر الأخرين بالحبر أوالصبغ أو الماء. & -6 \\
\hline & & & أتعمد كسر باب القاعد الدراسية عندما يصعب فتحه. & -7 \\
\hline & & & أميل الى تقطيع كراسي الموصلات العامة. & -8 \\
\hline & & & أكره اليوم الذي ولدت فيه. & -9 \\
\hline & & & أعض على شفتي عندما أنفعل. & -10 \\
\hline & & & أجد سعادة بإيذاء إخوتي وأخواتي & -11 \\
\hline & & & أقوم بتجريح المدرسين والسخرية منهم. & -12 \\
\hline & & & أستهزئ بالضيوف الزائدين. & -13 \\
\hline & & & أشعر بسعادة عندما أقوم بتعذيب حيوان ما. & -14 \\
\hline & & & أحب مشاهدة تعذيب الآخرين. & -15 \\
\hline & & & اميل الى مشاهدة أفلام العنف. & -16 \\
\hline & & & أحاول اللجوء الى الغش في الامتحانات. & -17 \\
\hline & & & أحاول الهرب من البيت. & -18 \\
\hline & & & أحاول بشتى الطرق ايذاءالجيران. & -19 \\
\hline & & & عندما يفرض علي شخص ما أمراً فاني أفعل عكس ما يريد. & -20 \\
\hline & & & أقوم باتلاف حاجيات الذين اكرههم & -21 \\
\hline & & & أصفع أي شخص يحاول إثارتي. & -22 \\
\hline & & & أرفع صوتي عندما أناقش الاخرين & -23 \\
\hline & & & أكون قاسيا مع أي شخص يعترض رغباتي. & -24 \\
\hline & & & أطلق غالباً تهديدات لاأقصد تنفيذها فعلاً. & -25 \\
\hline & & & أتلفظ عندما اغضب الفاظاً بذيئة. & -26 \\
\hline & & & أضرب أحياناً بعنف على المنضدة تعبيراً عن غضبي. & -27 \\
\hline & & & اهدد المدرس أو أشتمة في حال رسوبي. & -28 \\
\hline & & & أعمل على مضايقة والدي. & -29 \\
\hline & & & عندما ازدحام اضطر الى ضرب الآخرين لافساح المجال لي. & -30 \\
\hline & & & أشعر بالألم عندما أجد شخصيتاً ما يملك أشياء لاأملكها أنا. & -31 \\
\hline & & & أتعمد تخريب المتلكات الخاصة بالآخرين. & -32 \\
\hline & & & أشبع حاجاتي ولو على حساب الآخرين. & -33 \\
\hline & & & أقوم مع اصدقائي بتحطيم زجاج الصف. & -34 \\
\hline & & & أشعر بالاتياح عندما الحق الأذي بالآخرين. & -35 \\
\hline & & & أتعمد القاء الاوساخ في الددرسة والطرق العامة. & -36 \\
\hline & & & الطلبة الذين اكرههم لاأرغب اقامة العلاقات الاجتماعية معهم. & -37 \\
\hline & & & أشعر بسعادة عند أستعير كتب المكتبة ولا أردها. & -38 \\
\hline & & & اكتب على جدران المدرسة. & -39 \\
\hline & & & احاول تخريب دوات مياة المدرسة & -40 \\
\hline & & & 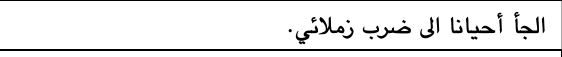 & -41 \\
\hline & & & أرد على انتقادات بالشتم. & -42 \\
\hline
\end{tabular}




\title{
The Impact of Selective Heuristic Program to Alleviate Aggressive Behavior of Elementary Students
}

\begin{abstract}
:
Aggressive behavior is a wide -spread phenomenon in our region which causes fear, concern and depression among our youth as result of the conflicts and tension which face the region. Thus, this phenomenon should be tackled scientifically to restore peace and stability and establish normal relations among people.

This study aims to;

1- Design an instructional program to handle aggressive behavior among ninth grade pupils.

2- ldentify the effect of this program in handing aggressive behavior among pupils.

The study tries to verify the following nil hypothesis;

There are statistically significant differences between the mean scores of the experimental group and the control group on the scale of aggressive behavior after implementing the instructional program.

To test the hypothesis, the researchers used an experimental group and control group with a pre and posttest. The sample consisted of 20 pupils randomly divided into two groups which they are experimental group and control group.

The researchers designed the following;

1- An instrument to measure aggressive behavior of 42 items. The instrument was assessed for face validity and reliability. Reliability was measured by split- half $(0,87)$.

2- An instructional programme based on planning, programming and budget and it included 14 sessions. The results showed that the instructional programmed had an effect on minimizing aggressive behavior among pupils. The researchers suggested some suggestions and recommendations in the light of the results.
\end{abstract}

Keywords: Selective Heuristic Program, Alleviate Aggressive Behavior, Elementary Students, Duhok. 